\title{
BUILDING ON A DECADE OF RESEARCH ON IT AND ORGANIZATIONS
}

\author{
Ojelanki K. Ngwenyama \\ Virginia Commonwealth University \\ U.S.A.
}

\author{
Lucas D. Introna \\ London School of Economics \\ United Kingdom
}

\author{
Michael D. Myers \\ University of Auckland \\ New Zealand
}

\section{Introduction}

At the close of this decade, and the "official beginning" of the new millennium, we continue to see the technologization of our social worlds, workplace, homelife and so on. In organizations, the focus of much of our research, IT, has become pervasive. The proliferation of electronic communication, collaborative, ERP, supply chain management and web technologies have all challenged our fundamental assumptions about organizations, organizing and work. Through the decade of the 1990s, IFIP W.G. 8.2 has responded to the challenges of demystifying these new information technologies and explicating their implications for everyday organizational life and activity. As a group of critically oriented scholars, we have been fortunate to engage with each other in a journey of inquiry during this last decade of the millennium that has been both exciting and rewarding. Throughout this decade, we have continued to inquire into the meaning of IT for everyday organizational life, engage in the key theoretical issues of our time and advance the state of knowledge of these new information technologies. In 1990, we began the decade of inquiry and critical debate with the Conference on Information 
Systems Research: Contemporary Approaches and Emergent Traditions, Copenhagen, Denmark. In Copenhagen, we reflected upon the path that our working group (8.2) had followed, and how the traditions of research and practice that we had cultivated over the previous decade would serve us in this decade. We examined our research approaches and methods in the light of some important research questions that were emerging. In the following year, we responded to the influx of new communication and collaborative technologies into organizations, and offered a critical analysis of them in our conference on Collaborative Work, Social Communications and Information Systems, Hanasaari, Finland (1991). In Hanasaari, we turned a critical lens on the concepts of communication and collaboration underlying the technologies of the time and revealed some of their shortcomings. We had some heated debates on the organizational implications of these technologies, raised questions about their naiveté and pushed to conceptualize new forms of communication and collaboration technologies to over come their shortcomings.

By 1992, we were in the midst of the group support era, and many organizations were acquiring group technologies (or thinking about acquiring them) to support various activities from strategy planning to systems development. In 1992, we entered this discourse with our Conference on the Impact of Computer Supported Technologies in Information Systems Development, Minneapolis, Minnesota, USA. Once again, we turned our critical lens on this technology and its uses and implications for organizational activities and life. In 1993, at Noordwijkerhout, The Netherlands, we continued this discourse and examined more closely the social and organizational issues in our Conference on Information Systems Development: Human, Social and Organizational Aspects. By the middle of the decade, those almost imperceptible incremental changes in organizations were becoming more visible due to continuous waves of implementation and use of new information technologies. In 1994, at the Conference on Information Technology and New Emergent Forms of Organizations, Ann Arbor, Michigan, USA, our discourse shifted somewhat to examine more closely how organizations were changing in the context of communication and collaboration technologies. We took up some of the strands of the debate from the 1991 conference, and re-examined our understanding of how these technologies are appropriated by individuals and are implicated in the reproduction of organizational structures and forms. In 1995, we expanded the focus to work and organizing at the Conference on Information Technology and Changes in Organizational Work, Cambridge, England. Our examination of changes in work and organizing also took a turn into postmodern deconstruction of concepts of organizing, work and technology. At that juncture, we once again reopened the discourse on the meaning of technology in everyday organizational life. Then in 1997, in keeping with tradition, we once again revisited our methods of inquiry. At the Conference Information Systems and Qualitative Research, Philadelphia, Pennsylvania, USA, we critically assessed our research methods in the light of current theoretical questions and tried to hone them for future research engagements. As Klein (in these proceedings) points out, the fundamental questions of how to systematically produce knowledge in our field of study persist without definitive resolution. We, the members of IFIP W.G. 8.2, close out the decade and the millennium, once again looking ahead at emerging issues, while addressing some pressing questions of the present. At our Helsinki, Finland, conference on Information Systems: Current Issues and Future Changes (1998), we engaged in a broad and at times deeply philosophical debate about information technology and our field at the turn of millennium. In this, our final 
conference of the decade, we address ourselves to some pressing questions that organizations are experiencing in implementing current process-oriented information technologies such as ERP and intranets. However, we take some time to reflect on the meaning of technology in everyday life, the path that we have followed in our inquiries and approaches to generalizing the knowledge that we obtain from them.

\section{Contributions}

The papers in these proceedings fall into two broad categories: critical reflections and field studies of IT implementations. The critical reflections focus on theory and method in IS research. The field studies of IT implementations vary from ERP systems, through intranets and collaboration technologies to electronic commerce.

\subsection{Critical Reflections}

Mark Poster's keynote talk promises an interesting panoramic analysis on the impact of IT on life globally. Mark will discuss how IT is facilitating a fundamental transformation in human interaction without regard to time, geography or national boundaries. He will outline some of the political implications of global communication systems such as the Internet.

In his insightful piece, Klein reflects on the development of IS research methods from the pre-1989 period to the present. He argues that the publication of three paradigmatic articles in Communications of the ACM in 1989 is a turning point in the discourse on methods in our field, a break with the dominant paradigm and explicit recognition of the existence of multiple paradigms in IS research. Klein briefly sketches the intellectual journey of IS research from its beginnings a mere thirty years ago. Its Kuhnian revolution from the hegemony of the orthodox method of science to its apparent abandonment and the present blooming of a thousand flowers of interpretivism. He cautions, however, that "interpretivists of all flavors should heed the often forgotten dictum that data without theory is blind and theory without data is empty." His challenge to us for the next decade is "to inject more methodological controls into interpretivism so that its results can gain the trust of researchers and practitioners alike while not losing its flexibility and sensitivity to situational differences."

Boland continues this critical reflection but takes us to an altogether different place. He examines how the notion of "space" has dominated, and still dominates, our field of research. He does a very interesting walkthrough of his own research to show how he attempted to make sense of images of "space." He recounts how he conceptualized the implementation problem as one in which mutual or shared understanding needs to develop. He shows how he attempted to make sense of the notion of "shared" understanding or knowledge through concepts such as frames and mappings. In the second section of the paper, Boland attempts to sketch out some of the reasons why the "spatialisation" of thought developed its prominence. He also introduces the work of Henri Bergson to show how the spatial triumphed over the temporal and what distortions this introduces. He concludes in a very frank way by stating: "So at this point I can only ask for giving more attention to the narrative mode without knowing exactly how to do 
so." He posits that the important issue for understanding implementation is to develop more temporal methods for representing and analyzing organizational phenomena. Methods that would "appreciate experience as it unfolds, that are sensitive to rhythm, tempo and construction in the flow of becoming."

As if in response to Klein's challenge, Baskerville and Lee take up the discourse on methodological controls in qualitative research. Specifically, they address the question of generalizing in qualitative research, commenting on the tentativeness of qualitative researchers to claim general contributions to the knowledge base of our field. In this piece, Baskerville and Lee outline different types of generalizing and discuss how each can lay claim to generality. Kaplan, Farzanfar and Freeman continue the critique of method with a discussion of the ethical dilemma the ethnographer faces in interviewing, recording and representing the worlds of the people he/she is studying. They present problems and findings from a study of the use of an intelligent interactive telephone system in a health care setting and discuss how individuals who use the service respond to it. Kaplan, Farzanfar and Freeman point to some open questions about attachment and alienation effects of IT and the ethical implications of some types of IT systems. Klein and Huynh address a fundamental problem of interpretive research, that is, how to systematically analyze and make sense of the mounds of empirical materials that are collected. Using empirical materials from a field study, they demonstrate how computer-aided language action analysis can assist in ethnographic analysis. They offer some advice on problems that researchers can expect when conduction such analysis.

\subsection{Field Studies}

Factors for successful implementation of ERP systems are outlined by Parr, Shanks and Darke. Hanseth and Braa discuss some of key issues of standardization of IT infrastructure that ERP systems, such as SAP, and collaboration systems, such as NOTES, impose on the implementing organization. Reporting on the first stage of a research program, Parr, Shanks and Darke seek to understand which factors might be necessary for the successful implementation of ERP systems. They identify ten candidate "necessary factors" for successful implementation, but admit that more research is needed to explore the relationship between these factors and broader contextual and processual issues. Hanseth and Braa provide us with a rich case study of Norsk Hydro, a very large manufacturing organization with diverse divisions and factories dispersed in many locations. The central "IS-Forum" and "Corporate Steering Group for IT" decide to establish a corporate-wide standard known as the "Hydro Bridge." The paper recounts a fascinating narrative of the attempts to make sense of what this means and how it will be, and is being, established. The narrative is essentially about the tension between our taken-for-granted notion of standards as universal objects shared by all in which there is no redundancy and no inconsistency, and the "always never $a$ standard" of every attempt to make it work. Sauer, Johnston, Karim, Marosszeky and Yetton discuss opportunities and barriers to implementing collaboration technologies in the Australian construction industry. They argue that although inter-organizational collaborative technologies offer competitive benefits to the construction industry (especially from cost reduction by reengineering the supply chain), this industry is slow to adopt these technologies. They explain this phenomenon by identifying industry-level condi- 
tions, which have influenced the low level of IT-based collaboration, and suggest industry-level interventions, which could stimulate IT adoption in future.

In his paper, O'Donovan suggests organizational disposition as an alternative narrative to organizational culture for investigating organizational change. He draws on the work of Heidegger in an attempt to develop a rather subtle argument about the way in which individuals generate an intersubjective awareness, as a prevailing mood, of their current situation that renders the possibilities for action available even before they have articulated it. This mood provides the implicit logic for action, the organizational disposition. O'Donovan uses this notion to argue how implementer strategy, and user resistance, gets weaved together in ways that make some implementations succeed and other fail. O'Donovan examines how organizational disposition affects the implementation process in two case studies. Scheepers examines the roles that the various actors play in the implementation process. He identifies from the literature five key roles that one would expect to find in Intranet implementation projects, then proceeds to carefully analyze three case studies in very different contexts to examine the role players, and their importance, in the initiation and implementation of intranet technology projects. He concludes that there are indeed reasons to believe that many of the traditional role taxonomies do not apply in the new context. Sarker and Lee investigate the proposition that computerized BPR tools have a positive influence on business reengineering effectiveness. Conger and Schultze illustrate with a case study how genre theory can be used to develop a conceptual framework for studying the practice of electronic commerce. Karsten, Lyytinen, Hurskainen and Koskelainen use the concepts of boundary objects and perspective taking and perspective making to elucidate how individuals interact and solve problems via IT in highly specialized and distributed engineering activities. In their case study, they show how these concepts can be useful for understanding the issues that would need to be solved if a certain relatively disorganized document set were to be redesigned to be a part of a collaborative information system, connected to data in ERP and other formalized systems. In a fair amount of detail, they analyze how the "technical specification document" for a paper machine (which could be a 500 to 600 page document) functions as a boundary object for perspective taking and as a conscription device for perspective making. They conclude that, although their study gives no directions as to how this dilemma could be solved in practice, it does draw attention to the dialectic nature of boundary objects and conscription devices in perspective making and perspective taking. Spitler and Gallivan discuss the role of IT in supporting learning in a consulting organization. They use the concept of legitimate and peripheral participation to examine how a culture of IT competence emerges over time and how individuals might be empowered (or disempowered) by their IT competence.

An underlying theme of all these field studies is the extent to which IT systems intervene in the social fabric of organizations. Given this situation, one might expect implementation methodologies to be deeply sensitive to the social transformation that takes place when these technologies are implemented. No so, say Hemingway and Gough. Although debate for the next generation of development methodologies is ongoing, researchers still have problems incorporating the concept of social transformation in systems development methods and practice. Hemingway and Gough propose a general structure for such a methodology based on socio-cognitive theory and give an indication of its logic and possibilities. They acknowledge that their work is still very 
much "in progress" but defend it as a reasonable attempt to address not only theory but also development practice.

\section{Concluding Remarks}

While this volume can in no way sum up the contributions that IFIP W.G. 8.2 has made to the field of information systems during the last ten years, it does mark the end of the decade and millennium. It builds on a decade of achievements in research on IT and organizations and gives an idea of some of the unsolved problems that we will take into the next millennium. We hope that you find it informative and exciting to read. We hope that those attending this 1999 conference on New Information Technologies in Organizational Processes: Field Studies and Theoretical Reflections on the Future of Work find the discussions stimulating.

\section{About the Authors}

Ojelanki K. Ngwenyama is Associate Professor and Director of the Center of Excellence in ERP Research at Virginia Commonwealth University; Docent at University of Jyväskylä, Finland; Visiting Research Professor at Aalborg University, Denmark; and Extraordinary Professor at University of Pretoria, South Africa. He is a co-founder of the Collaboratory for Research on Electronic Work (CREW), University of Michigan. Between 1990 and 1997, Ojelanki was a faculty member of The University of Michigan Business School. He is a critical theorist whose research focuses on how people engage information technology in organizations. He holds a Ph.D. in Computer Science and Information Systems from The Thomas J. Watson School of Engineering, State University of New York. He is a member of the Editorial Board of the Journal of the Association of Information Systems and Associate Editor of the journal Information Technology \& People. He is co-editor of the book Transforming Organizations With Information Technology, North Holland, 1994. Ojelanki can be reached by e-mail at ojelanki@isy.vcu.edu.

Lucas D. Introna is Lecturer in Information Systems at the London School of Economics and Political Science and Visiting Professor of Information Systems at the University of Pretoria, South Africa. He is associate editor of Information Technology \& People and editor of Ethics and Information Technology. He is an active member of IFIP W.G. 8.2, The Society for Philosophy in Contemporary World (SPCW), the International Sociological Association WG01 on Sociocybernetics, and a number of other academic and professional societies. His most recent work includes a book, Management, Information and Power, published by Macmillan, and he has published widely in the best IS journals and conference proceeding on a variety of topics such as theories of information, information technology and ethics, autopoiesis and social systems, and virtual organizations. Lucas can be reached at l.introna@les.ac.uk.

Michael D. Myers is Associate Professor in the Department of Management Science and Information Systems at the University of Auckland, New Zealand. His research interests are 
in the area of information systems development, qualitative research methods in information systems, and the social and organizational aspects of information technology. His papers have appeared in a wide range of journals, including Accounting, Management and Information Technologies, Communications of the ACM, Ethics and Behavior, Information Systems Journal, Information Technology and People, Journal of Information Technology, Journal of Management Information Systems, MIS Quarterly and MISQ Discovery. He is co-author of two books, including New Zealand Cases in Information Systems (with J. Sheffield, Pagination Publishers, $2^{\text {nd }}$ edition, 1992). Michael is Editor of the ISWorld Section on Qualitative Research, an Associate Editor of the Information Systems Journal, an Associate Editor of MIS Quarterly, and on the Editorial Boards of Communications of the AIS, Information Technology \& People and Journal of Systems and Technology. Michael can be reached by e-mail at m.myers@auckland.ac.nz. 